\title{
Auto-offsetting and -referencing in biomolecular NMR experiments
}

\author{
Shanmin Zhang* \\ Shanghai key Laboratory of Magnetic Resonance, Department of Physics, East China Normal University, Shanghai, China; \\ *Corresponding Author: shanminz@hotmail.com
}

Received 16 April 2011; revised 1 May 2011; accepted 8 July 2011.

\begin{abstract}
A frequency ratio RatioXH associated with two carrier frequencies in $\mathrm{ppm}$ is introduced for achieving auto-offsetting and -referencing (AOR) in biomolecular NMR. Once the center of ${ }^{1} \mathrm{H}$ is referenced, all the offsets in other dimensions are automatically determined and the centers of the spectral widths provide accurate indirect references. Since the scale in ppm is independent of the magnetic field strength, the AOR does not require manually updating carrier frequencies from time to time, making the multidimensional NMR experiments greatly simplified and reliable. It is extremely valuable when molecules need to be run a large number of experiments at different times and the data (chemical shifts, for example) need to be compared with each other. In AOR, the error arising from improper referencing of ${ }^{1} \mathrm{H}$ is handed down in the same amount to the other nuclei being referenced. This error-inheritance provides a measure of accuracy in indirect referencing. The temperature dependence of the frequency ratio of DSS is derived with the first-order approximation and it can be used for temperature dependent AOR. For nuclei other than ${ }^{13} \mathrm{C}$, certain frequency ratios regarding TMS need to be derived (rather than measured) based on the recommended frequency ratios of DSS, thus avoiding conflicts and unifying the two standards.
\end{abstract}

Keywords: Auto-Offsetting and -Referencing; Indirect Referencing; Frequency Ratios;

Biological NMR

\section{INTRODUCTION}

In NMR, the resonance frequency of nuclei in a strong magnetic field $\left(\mathbf{B}_{0}\right)$ is determined by the Zeeman $\left(\mathcal{} \mathbf{B}_{0}\right)$ and shielding $\left(\boldsymbol{B}_{0} \sigma\right)$ interactions [1,2]. The shielding interaction is induced by the nearby electrons precessing at their own Larmor frequencies, which produce a very small magnetic field at the site of the nucleus. As the Larmor frequency of the electrons, it is also proportional to $\mathrm{B}_{0}$. The shielding coefficient $\sigma$ is referred to as chemical shift, which contains rich information about local molecular structures in solids [3] (chemical shift anisotropy) and in liquids (isotropic part only).

Due to the nature that both of the Zeeman and shielding interactions are proportional to $\mathrm{B}_{0}$, the NMR spectra obtained under different field strengths are comparable in terms of a universal scale in ppm. In comparison, a reference molecule, such as dimethylsilapentane sulfonic acid (DSS, $\mathrm{C}_{6} \mathrm{H}_{16} \mathrm{O}_{3} \mathrm{SSi}$ ) or tetramethylsilane (TMS, $\left.\left(\mathrm{CH}_{3}\right)_{4} \mathrm{Si}\right)$ is often used, where the methyl ${ }^{1} \mathrm{H}$ and ${ }^{13} \mathrm{C}$ are well shielded by the low electronegativity of the silicon. As a result, their resonances are shifted to far upper field and are both defined as 0 ppm. For most naturally occurring molecules, the NMR peaks referenced to DSS or TMS appear in the positive region with increasing frequency [4-6].

Since the reference peaks depend on solvent, temperature, $\mathrm{pH}$ (measured internally), and susceptibility (measured externally), direct referencing becomes problematic sometimes. The situation can be alleviated considerably by using a frequency ratio $R_{\mathrm{CH}}(0)$ between the ${ }^{13} \mathrm{C}$ and ${ }^{1} \mathrm{H}$ (both defined as $0 \mathrm{ppm}$ ) of a reference molecule in order to reference ${ }^{13} \mathrm{C}$ from ${ }^{1} \mathrm{H}$ [7-9]. This scheme is referred to as indirect referencing in the NMR literature. The recommended ratios for DSS and TMS are $R_{\mathrm{CH}}^{\mathrm{DSS}}(0)=0.251449530 \quad[8-10]$ and $R_{\mathrm{CH}}^{\mathrm{TMS}}(0)=$ 0.25145020 [11], respectively. The two ratios are very close and so are the differences of their ${ }^{1} \mathrm{H}$ and ${ }^{13} \mathrm{C}$ chemical shifts, respectively. On the scale of TMS, the ${ }^{1} \mathrm{H}$ chemical shift of DSS (both molecules in the same aqueous solution), $\delta_{\mathrm{H}}^{\text {DSS-TMS }}=0.0173 \mathrm{ppm}$ [12]. The accuracy of the indirect referencing relies exclusively on the ${ }^{1} \mathrm{H}$ referencing, which is much easier to handle, es- 
pecially for biomolecular NMR experiments with inverse $\left({ }^{1} \mathrm{H}\right)$ detection.

The indirect referencing has been extended to nuclei other than ${ }^{13} \mathrm{C}$, where the frequency ratio $R_{\mathrm{XH}}(0)$ is measured between the two nuclei, $\mathrm{X}$ and ${ }^{1} \mathrm{H}$ in two different molecules. Conflicting results may arise if both DSS and TMS standards are used to reference a nucleus other than ${ }^{13} \mathrm{C}$ due to incompatibility of the two measured ratios. To avoid the conflict, only one of the ratios should be measured and the other must be calculated.

Experimentally, the carrier frequencies, which irradiate at the centers of the spectral widths in quadrature detection [13] and are intimately related to frequency referencing, play important roles because misplaced carrier frequency may introduce improper excitation and poor decoupling. Further more, correct carrier frequencies must be determined before the experiments although referencing can be done after data collection. If the ${ }^{1} \mathrm{H}$ carrier frequency can be set correctly, offsetting and referencing in all the indirectly detected dimensions can be done automatically. This method is referred to autooffsetting and -referencing (AOR). A convenient way to do AOR is to define the ratios between carrier frequencies in terms of ppm rather than frequency. Since ppm is independent of magnetic field strength and it remains the same from time to time, the AOR simplifies NMR experiments, saves considerable time, renders proper excitation and decoupling, and provides accurate indirect referencing. With slight modification, it can also be applied to direct detection of nuclei other than ${ }^{1} \mathrm{H}$.

\section{THE RATIOS BETWEEN CARRIER FREQUENCIES}

In most biomolecular NMR experiments, the chemical shift regions to be excited are often known in terms of ppm, while the carrier frequencies in terms of $\mathrm{Hz}$ are not. Besides, ppm is independent of the magnetic field strength and needs not chang from time to time. It would be much simpler and more convenient to input the spectral centers in ppm rather than in Hz. This can be accomplished by introducing a frequency ratio, RatioXH, between the carrier frequency of ${ }^{1} \mathrm{H}, \mathrm{CFH}$ (in ppm) of the directly detected dimension, and the carrier frequency of an $\mathrm{X}$ nucleus, CFX (in ppm) in the indirect dimension.

As shown in Figure 1, the ratio between the two carrier frequencies can be expressed as

$$
\begin{aligned}
\text { RatioXH } & =\frac{v_{\mathrm{X}}}{v_{\mathrm{H}}}=\frac{\mathrm{CFX} \times v_{\mathrm{X}}(0) \times 10^{-6}+v_{\mathrm{X}}(0)}{\mathrm{CFH} \times v_{\mathrm{H}}(0) \times 10^{-6}+v_{\mathrm{H}}(0)} \\
& =R_{\mathrm{XH}}(0) \frac{\mathrm{CFX}+10^{6}}{\mathrm{CFH}+10^{6}}
\end{aligned}
$$

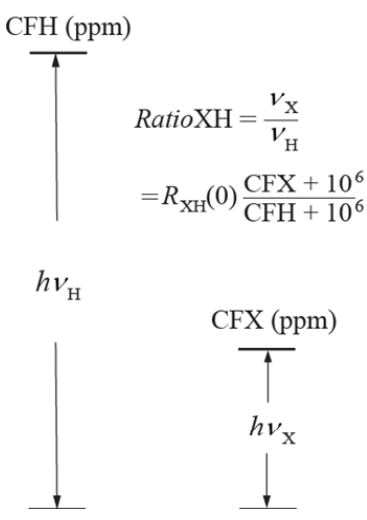

Figure 1. Energy levels for ${ }^{1} \mathrm{H}$ and $\mathrm{X}$ nuclei at the centers of their spectral widths, where $v_{\mathrm{H}}$ and $v_{\mathrm{X}}$ are the two carrier frequencies, respectively. At both centers, the chemical shifts in ppm are defined as CFH and CFX, respectively.

where $R_{\mathrm{XH}}(0)=v_{\mathrm{X}}(0) / v_{\mathrm{H}}(0)$ is the frequency ratio between $\mathrm{X}$ and ${ }^{1} \mathrm{H}$, both defined as $0 \mathrm{ppm}$. For referencing ${ }^{13} \mathrm{C}, R_{\mathrm{CH}}^{\mathrm{DSS}}(0)$ or $R_{\mathrm{CH}}^{\mathrm{TMS}}(0)$ can be used in order to make the referencing compatible with DSS or TMS standard, respectively.

Unlike any other frequency ratios, RatioXH is, in general, not fixed and depends on both CFX and CFH, which are related to particular experiments. The usefulness of this ratio relies on the fact that it is derived from the ppm values rather than the actual frequencies, simplifying experiments considerably. In the RatioXH, $\mathrm{CFH}$ can be determined if any of the ${ }^{1} \mathrm{H}$ peak is referenced while CFX is usually a known value, $174 \mathrm{ppm}$ for ${ }^{13} \mathrm{CO}$ for example.

Some of the common frequency ratios in double- and triple-resonance experiments are listed in Table 1. They can be used as a quick check of experimental settings.

\section{DETERMINATION OF OFFSETS IN THE INDIRECT DIMENSIONS}

Since the NMR magnetic field is constantly drifting (several Hz per hour for instance), the frequency offsets often need to be adjusted for accommodating the drifting of the magnetic field. The ${ }^{1} \mathrm{H}$ offset is the most convenient one to set up in experiments with inverse detection because the spectrum can be obtained directly. Once it is done, all the other offsets can be derived by the NMR instrument from the RatioXH. The AOR can be achieved in experiments by properly defining the offsets, ${ }^{13} \mathrm{C}$ offset (dofC) for instance, which is required by the CFC and can be calculated by the NMR instrument using the relationship

$$
\text { RatioCH }=\frac{v_{\mathrm{C}}}{v_{\mathrm{H}}}=\frac{d f r q+d o f \mathrm{C}}{s f r q}
$$


Table 1. The frequency ratios (calculated from Eq.1) in some of the frequently used biomolecular NMR experiments, where $\mathrm{H}_{2} \mathrm{O}$ (in $90 \% \mathrm{H}_{2} \mathrm{O} / 10 \% \mathrm{D}_{2} \mathrm{O}$ ) at $25^{\circ} \mathrm{C}$ is used as a proton reference or $\mathrm{CFH}=4.80 \mathrm{ppm}$.

\begin{tabular}{ccccc}
\hline & $\begin{array}{c}\text { CFC } \\
(\mathrm{ppm})\end{array}$ & $\begin{array}{c}\text { CFN } \\
(\mathrm{ppm})\end{array}$ & RatioCH & RatioNH \\
\hline HSQC & & 120 & & 0.101340791 \\
HNCA & 56 & 120 & 0.251462404 & 0.101340791 \\
HNCO & 174 & 120 & 0.251492075 & 0.101340791 \\
HNCACB & 46 & 120 & 0.251459890 & 0.101340791 \\
HCCH_TOCSY & 35 & 120 & 0.251457124 & 0.101340791 \\
\hline
\end{tabular}

or

$$
d o f \mathrm{C}=\text { RatioCH } \times s f r q-d f r q,
$$

where sfrq, according to Varian's notation, is the transmitter frequency of the observe channel used here for ${ }^{1} \mathrm{H}$ and $d$ frq is the first decouple frequency used here for ${ }^{13} \mathrm{C}$. In general, sfrq and $d f r q$ depend on magnetic field strength, lock frequency, solvent, etc., while RatioCH should be independent of these parameters and it must remain the same from time to time. To reference the $\mathrm{CFH}$, only the transmitter offset (tof) needs to be adjusted and sfrq is updated every time when a new tof is entered. On the other hand, dofC, calculated on the fly, varies accordingly in order to make the RatioCH invariant. The calculated dofC is then used at the beginning of the pulse sequence as an additional offset of the ${ }^{13} \mathrm{C}$ channel, making the carrier frequency $(d f r q+d o f C)$ irradiating exactly on the desired center, CFC. The CFC in turn serves as an accurate indirect reference for ${ }^{13} \mathrm{C}$ dimension.

\section{ERROR-INHERITANCE IN THE INDIRECT REFERENCING}

In the indirect referencing, the error occurring in referencing $\mathrm{CFH}$ will cause an error in the calculation of $d o f C$, which can be determined by the following relation,

$$
\begin{aligned}
\Delta \text { dofC } & =\Delta \text { RatioCH } \times \text { sfrq } \\
& =-\frac{\text { RatioCH }}{\mathrm{CFH}+10^{6}} \times \text { sfrq } \times \Delta \mathrm{CFH} .
\end{aligned}
$$

The error in ppm is then

$$
\Delta \mathrm{CFC}=-\frac{\Delta d o f \mathrm{C}}{v_{\mathrm{C}}(0)} \times 10^{6} \approx \Delta \mathrm{CFH} .
$$

The above equation is referred to as error-inheritance and it shows that the same amount of error in ppm in the ${ }^{1} \mathrm{H}$ referencing is inherited by ${ }^{13} \mathrm{C}$ referencing. The error, however, is reduced by a factor of $\gamma_{H} / \gamma_{C}$ in terms of $\mathrm{Hz}$. It is therefore better to use a nucleus with a higher geomagnetic ratio to reference the others. These conclusions, including Eqs.2a and $\mathbf{2} \mathbf{b}$, also hold between ${ }^{1} \mathrm{H}$ and any other nuclei, such as ${ }^{15} \mathrm{~N}$.

Both $\triangle \mathrm{CFH}$ and $\triangle \mathrm{CFC}$ in Eq.4 are defined as referenced - real chemical shifts. For instance, if the ${ }^{1} \mathrm{H}$ in $90 \% \mathrm{H}_{2} \mathrm{O} / 10 \% \mathrm{D}_{2} \mathrm{O}$ is referenced as 4.90 ppm instead of $4.80 \mathrm{ppm}$ by mistake, CFH $=4.90 \mathrm{ppm}$ is used in Eqs.1 and $\mathbf{2 b}$ and $\triangle \mathrm{CFH}=(4.90-4.80) \mathrm{ppm}=0.1 \mathrm{ppm}$. As a result, dofC in Eq.2b becomes smaller because of a relatively larger $\mathrm{CFH}$ in the denominator of RatioCH defined in Eq.1. The ${ }^{13} \mathrm{CO}$ RF field is then on-resonance at $173.9 \mathrm{ppm}$ instead of $174 \mathrm{ppm}$. Yet, this center is still referenced as $174 \mathrm{ppm}$ since $\mathrm{CFC}=174 \mathrm{ppm}$ is used in Eq.2b. Under this circumstance, $\triangle \mathrm{CFC}=(174-173.9)$ $\mathrm{ppm}=0.1 \mathrm{ppm}$, or $\Delta \mathrm{CFC}=\Delta \mathrm{CFH}$, in agreement with the definition of error-inheritance.

\section{RELATIONSHIP BETWEEN THE REFERENCES TO DSS AND TMS}

The proton chemical shift of DSS on the scale of TMS (both in aqueous solution) has been determined [12],

$$
\begin{aligned}
\delta_{\mathrm{H}}^{\mathrm{DSS}-\mathrm{TMS}} & =\frac{v_{\mathrm{H}}^{\mathrm{DSS}}(0)-v_{\mathrm{H}}^{\mathrm{TMS}}(0)}{v_{\mathrm{H}}^{\mathrm{TMS}}(0)} \times 10^{6} \\
& =0.0173 \mathrm{ppm} .
\end{aligned}
$$

From the above equation, the relative reference in ${ }^{13} \mathrm{C}$ can be derived based on the frequency ratios of DSS and TMS,

$$
\begin{aligned}
\delta_{\mathrm{C}}^{\mathrm{DSS}-\mathrm{TMS}} & =\frac{v_{\mathrm{C}}^{\mathrm{DSS}}(0)-v_{\mathrm{C}}^{\mathrm{TMS}}(0)}{v_{\mathrm{C}}^{\mathrm{TMS}}(0)} \times 10^{6} \\
& =\left[\frac{R_{\mathrm{CH}}^{\mathrm{DSS}}(0) v_{\mathrm{H}}^{\mathrm{DSS}}(0)}{R_{\mathrm{CH}}^{\mathrm{TMS}}(0) v_{\mathrm{H}}^{\mathrm{TMS}}(0)}-1\right] \times 10^{6} \\
& =\frac{R_{\mathrm{CH}}^{\mathrm{DSS}}(0)}{R_{\mathrm{CH}}^{\mathrm{TMS}}(0)}\left(\delta_{\mathrm{H}}^{\mathrm{DSS}-\mathrm{TMS}}+10^{6}\right)-10^{6} \\
& =-2.6472 \mathrm{ppm} .
\end{aligned}
$$

Because $\delta_{\mathrm{C}}^{\text {DSS-TMS }}$ is negative, the ${ }^{13} \mathrm{C}$ peak of DSS is located in the upper field than that of TMS. The separation between the two reference peaks in ${ }^{13} \mathrm{C}$ is much greater than in ${ }^{1} \mathrm{H}$. Given the relative chemical shifts $\delta_{\mathrm{H}}^{\text {DSS-TMS }}$ and $\delta_{\mathrm{C}}^{\text {DSS-TMS }}$, the ${ }^{13} \mathrm{C}$ and ${ }^{1} \mathrm{H}$ chemical shifts referenced to DSS and to TMS can be conveniently converted from one to the other.

\section{THE FREQUENCY RATIOS FOR NUCLEI OTHER THAN ${ }^{13} \mathrm{C}$}

The frequency ratio between an $\mathrm{X}$ nucleus used as a reference in a molecule and ${ }^{1} \mathrm{H}$ in DSS is defined as

$$
R_{\mathrm{XH}}^{\mathrm{DSS}}(0)=\frac{v_{\mathrm{X}}(0)}{v_{\mathrm{H}}^{\mathrm{DSS}}(0)},
$$


where $v_{\mathrm{X}}(0)$ is the transition frequency of the $\mathrm{X}\left(\neq{ }^{13} \mathrm{C}\right)$ nucleus used as a reference. The definition of Eq.7 can also be applied to TMS. So far a number of $R_{\mathrm{XH}}^{\mathrm{DSS}}(0)$ have been determined as shown in Table 2 [4,7,11,12,14]. It is important to note that conflicting results may arise if both measured values of $R_{\mathrm{XH}}^{\mathrm{DSS}}(0)$ and $R_{\mathrm{XH}}^{\mathrm{TMS}}(0)$ are used to reference an $\mathrm{X}$ peak. In other words, indirect referencing using $R_{\mathrm{XH}}^{\mathrm{DSS}}(0)$ and $R_{\mathrm{XH}}^{\mathrm{TMS}}(0)$ may be different even though both reference the same nucleus $\mathrm{X}$ that belongs neither to DSS nor to TMS. The conflict is caused by differences in samples, experimental conditions, and improper measurements of the two ratios. To resolve this issue, $R_{\mathrm{XH}}^{\mathrm{DSS}}(0)$ may be used as references and from which the corresponding $R_{\mathrm{XH}}^{\mathrm{TMS}}(0)$ are derived. To this end, the relationship between the two ratios needs to be established as shown in the following.

From Eq.7, it follows

$$
\frac{R_{\mathrm{XH}}^{\mathrm{TMS}}(0)}{R_{\mathrm{XH}}^{\mathrm{DSS}}(0)}=\frac{v_{\mathrm{H}}^{\mathrm{DSS}}(0)}{v_{\mathrm{H}}^{\mathrm{TMS}}(0)},
$$

or

$$
\begin{aligned}
R_{\mathrm{XH}}^{\mathrm{TMS}}(0) & =\frac{\delta_{\mathrm{H}}^{\mathrm{DSS}-\mathrm{TMS}} v_{\mathrm{H}}^{\mathrm{TMS}}(0) \times 10^{-6}+v_{\mathrm{H}}^{\mathrm{TMS}}(0)}{v_{\mathrm{H}}^{\mathrm{TMS}}(0)} R_{\mathrm{XH}}^{\mathrm{DSS}}(0) \\
& =\left(1+\delta_{\mathrm{H}}^{\mathrm{DSS}-\mathrm{TMS}} \times 10^{-6}\right) R_{\mathrm{XH}}^{\mathrm{DSS}}(0) .
\end{aligned}
$$

To avoid conflict, only one of the ratios should be measured. It can be shown from Eq.8b that RatioXH in Eq.1 (where CFN = 120 ppm while $\mathrm{CFH}=4.80 \mathrm{ppm}$ for DSS and 4.8173 ppm for TMS) is invariant (RatioNH = 0.101340791 ) or irrespective to DSS and TMS standards, thus preserving experimental setting as well as indirect referencing. As a result, the chemical shift of an $\mathrm{X} \mathrm{nu}$ cleus, either referenced to DSS or to TMS, is the same. Some of the $R_{\mathrm{XH}}^{\mathrm{TMS}}(0)$ calculated with Eq.8b are listed in Table 2.

\section{7. ${ }^{1} \mathrm{H}$ REFERENCE USING WATER}

In biomolecular NMR, $90 \% \mathrm{H}_{2} \mathrm{O} / 10 \% \mathrm{D}_{2} \mathrm{O}$ is often used as a solvent, where the proton in $\mathrm{H}_{2} \mathrm{O}$ can be used as a reference. The advantage to use $\mathrm{H}_{2} \mathrm{O}$ as a reference lies mainly in its large volume $(\sim 50 \mathrm{M})$. Because of the overwhelming quantity, the water signal is extremely strong and the chemical shift is less affected by the other molecules.

On the other hand, the temperature dependence of $\mathrm{H}_{2} \mathrm{O}$ chemical shift is relatively large. At $25^{\circ} \mathrm{C}$, the measured water resonance $\delta_{\mathrm{H}_{2} \mathrm{O}}=4.80 \mathrm{ppm}$ relative to the DSS (0 ppm) from a commercial sample of $2 \mathrm{mM}$ sucrose $+0.5 \mathrm{mM}$ DSS in $90 \% \mathrm{H}_{2} \mathrm{O} / 10 \% \mathrm{D}_{2} \mathrm{O}$ (Cambridge Isotope Laboratories, Inc). This peak shifts almost linearly at $-0.0088 \mathrm{ppm} /{ }^{\circ} \mathrm{C}$. If the proton peak of DSS at $25^{\circ} \mathrm{C}$ is used as a reference, the $\mathrm{CFH}$ of $\mathrm{H}_{2} \mathrm{O}$ as a
Table 2. The frequency ratios of some compounds commonly used in indirect referencing, where i and e stand for internal and external, respectively. $\delta_{\mathrm{H}}^{\text {DSs-TMS }}=0.0173 \mathrm{ppm}$ is used in the calculation of $R_{\mathrm{XH}}^{\mathrm{TMS}}(0)$.

\begin{tabular}{ccc}
\hline & Frequency Ratio & References \\
\hline$R_{\mathrm{CH}}^{\mathrm{DSS}}(0)$ & 0.251449530 & DSS [7] \\
$R_{\mathrm{NH}}^{\mathrm{DSS}}(0)$ & 0.101329118 & $\mathrm{NH}_{3}(\mathrm{e})$ \& DSS [7] \\
$R_{\mathrm{PH}}^{\mathrm{DSS}}(0)$ & 0.404808638 & $\left(\mathrm{CH}_{3} \mathrm{O}\right)_{3} \mathrm{PO}(\mathrm{I})$ \& DSS [12] \\
$R_{\mathrm{DH}}^{\mathrm{DSS}}(0)$ & 0.153506088 & DSS [11] \\
$R_{\mathrm{FH}}^{\mathrm{DSS}}(0)$ & 0.940866982 & TFA (Trifluoroacetic Acid) (e) [14] \\
$R_{\mathrm{CH}}^{\mathrm{TMS}}(0)$ & 0.25145020 & TMS [4] \\
$R_{\mathrm{NH}}^{\mathrm{TMS}}(0)$ & 0.101329120 & Calculated with Eq.8b \\
$R_{\mathrm{PH}}^{\mathrm{TMS}}(0)$ & 0.404808645 & Calculated with Eq.8b \\
$R_{\mathrm{DH}}^{\mathrm{TMS}}(0)$ & 0.153506091 & Calculated with Eq.8b \\
$R_{\mathrm{FH}}^{\mathrm{TMS}}(0)$ & 0.940866998 & Calculated with Eq.8b \\
\hline
\end{tabular}

function of temperature can be described by

$$
\mathrm{CFH}=4.80-(T-25) \times 0.0088(\mathrm{ppm}),
$$

where $T$ is the sample temperature in ${ }^{\circ} \mathrm{C}$.

\section{TEMPERATURE DEPENDENT FREQUENCY RATIO AND AOR}

The frequency ratio $R_{\mathrm{XH}}(0)$ (Eq.1) is defined at $25^{\circ} \mathrm{C}$. Since both transition frequencies, $v_{\mathrm{X}}(0)$ and $v_{\mathrm{H}}(0)$, depend on temperature, their ratio also depends on temperature

$$
\begin{aligned}
R_{\mathrm{XH}}(0, \Delta T) & =\frac{v_{\mathrm{X}}(0, \Delta T)}{v_{\mathrm{H}}(0, \Delta T)} \\
& \approx \frac{v_{\mathrm{X}}(0)}{v_{\mathrm{H}}(0)}+\frac{v_{\mathrm{X}}^{\prime} v_{\mathrm{H}}(0)-v_{\mathrm{H}}^{\prime} v_{\mathrm{X}}(0)}{v_{\mathrm{H}}^{2}(0)} \Delta T \\
& =R_{\mathrm{XH}}(0)+\left[\frac{v_{\mathrm{X}}^{\prime}-R_{\mathrm{XH}}(0) v_{\mathrm{H}}^{\prime}}{v_{\mathrm{H}}(0)}\right] \Delta T \\
& =R_{\mathrm{XH}}(0)\left\{1+\left[\frac{v_{\mathrm{X}}^{\prime}}{v_{\mathrm{X}}(0)}-\frac{v_{\mathrm{H}}^{\prime}}{v_{\mathrm{H}}(0)}\right] \Delta T\right\},
\end{aligned}
$$

where $v_{\mathrm{X}}^{\prime}=\left.\left(d v_{\mathrm{X}} / d T\right)\right|_{T=25}$ and $\Delta T=(T-25)$. Here, only the first-order correction is taken into account because the variation of the ratio is small.

If both $v_{\mathrm{X}}^{\prime}$ and $v_{\mathrm{H}}^{\prime}$ are expressed in terms of ppm rather than $\mathrm{Hz}$, the temperature dependence of the frequency ratio becomes

$$
R_{\mathrm{XH}}(0, \Delta T)=R_{\mathrm{XH}}(0)\left\{1+\left[\frac{v_{\mathrm{X}}^{\prime}-v_{\mathrm{H}}^{\prime}}{10^{6}}\right] \Delta T\right\} .
$$


According to our measurements of DSS with the same sample mentioned in the previous section, $v_{\mathrm{C}}^{\prime}=0.00448$ $\mathrm{ppm} /{ }^{\circ} \mathrm{C}$ and $v_{\mathrm{H}}^{\prime}=0.00048 \mathrm{ppm} /{ }^{\circ} \mathrm{C}$ near $25^{\circ} \mathrm{C}$. It follows that temperature dependence of the frequency ratio of DSS near $25^{\circ} \mathrm{C}$

$$
R_{\mathrm{CH}}^{\mathrm{DSS}}(0, \Delta T)=R_{\mathrm{CH}}^{\mathrm{DSS}}(0)\left[1+4.0 \times 10^{-9} \Delta T\right] .
$$

From Eqs.1 and 12, the temperature dependent ratio between carrier frequencies can be derived,

$$
\text { RatioXH }(\Delta T)=R_{\mathrm{XH}}(0, \Delta T) \frac{\mathrm{CFX}+10^{6}}{\mathrm{CFH}+10^{6}} .
$$

Based on the above results, the temperature dependent AOR can be achieved. As an example, we consider an experiment of $\mathrm{HCCH}$ _TOCSY with a CFC at $35 \mathrm{ppm}$ (Table 1) and a sample with $90 \% \mathrm{H}_{2} \mathrm{O} / 10 \% \mathrm{D}_{2} \mathrm{O}$ at a temperature of $35^{\circ} \mathrm{C}$. From Eq.12, the temperature dependent ratio can be derived $R_{\mathrm{CH}}^{\mathrm{DSS}}(0, \Delta T)=0.251449540$. According to the temperature dependence of $\mathrm{H}_{2} \mathrm{O}$ (Eq.9), the $\mathrm{CFH}=4.80-(T-25) \times 0.0088=4.712 \mathrm{ppm}$. At this moment, the temperature dependence of DSS has not been taken into account. Given the results of $v_{\mathrm{C}}^{\prime}=$ $0.00448 \mathrm{ppm} /{ }^{\circ} \mathrm{C}$ and $v_{\mathrm{H}}^{\prime}=0.00048 \mathrm{ppm} /{ }^{\circ} \mathrm{C}$, both centers can be converted in order to reference DSS at $35^{\circ} \mathrm{C}$, i.e.,

$$
\begin{aligned}
\mathrm{CFH} & =4.80-\Delta T \times 0.0088-v_{\mathrm{H}}^{\prime} \Delta T \\
& =4.7072 \mathrm{ppm},
\end{aligned}
$$

and

$$
\begin{aligned}
\mathrm{CFC} & =35-v_{\mathrm{C}}^{\prime} \Delta T \\
& =34.9552 \mathrm{ppm} .
\end{aligned}
$$

with $R_{\mathrm{CH}}^{\mathrm{DSS}}(0, \Delta T), \mathrm{CFH}$ and CFC (Eqs.14 and 15), all referenced to DSS at $35^{\circ} \mathrm{C}$, the ratio of the carrier frequency can be derived from Eq.13, leading to a temperature dependent AOR with the $\operatorname{RatioCH}(\Delta T)=$ 0.251457146 .

\section{EXPERIMENTAL}

To test the scheme of AOR with proper ratios of carrier frequencies, a gradient enhanced HNCO experiment was performed with and without AOR. As described above, dofC and $d o f N$ are defined in the pulse sequence and they are calculated with Eq.2b. These two values are then used as additional offsets inserted at the beginning of the pulse sequence: decoffset $(d o f C+d o f)$ and dec2offset $(d o f N+d o f 2)$ in Varian's notation. To convert any Varian HCN triple-resonance sequence to an AOR variant using the DSS standard, the additions to the $\mathrm{C}$ code is shown below:

double

$\mathrm{CFH}=$ getval(“CFH”),

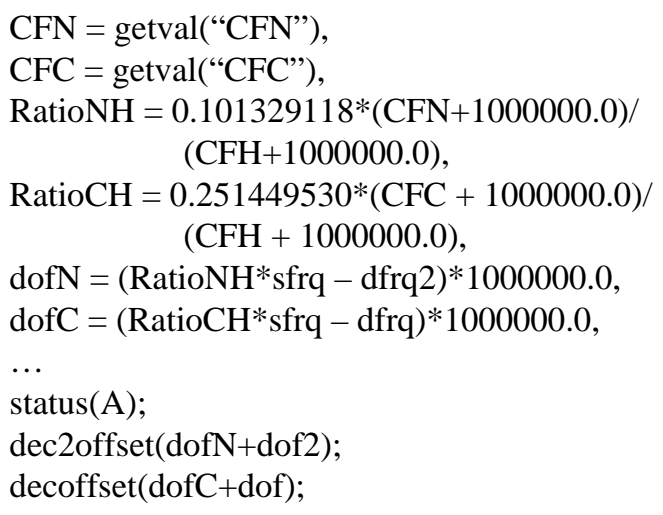

In addition, the dg panel of the VnmrJ is modified slightly (Figure 2), where, in contrast to the conventional display, CFH, CFC, and CFN in ppm are added.

In AOR experiments, the water peak can be served as ${ }^{1} \mathrm{H}$ reference and is set on-resonance. To determine the proton offset (tof), a separate single pulse sequence is used with an acquisition time of $4 \mathrm{~s}$. A flip-angle about $15^{\circ}$ is used instead of $90^{\circ}$ to avoid ADC overflow and the effect of radiation damping at high magnetic field $[1,15]$. The $\mathrm{H}_{2} \mathrm{O}$ spectrum is shown in Figure 3, where the value of tof is determined and then used in the experiments with $\mathrm{AOR}$. At $25^{\circ} \mathrm{C}, \mathrm{CFH}$ is set to $4.80 \mathrm{ppm}$. The offsets $d o f C$ and $d o f N$ are determined automatically from the desired values $(\mathrm{CFC}=174 \mathrm{ppm}$ and $\mathrm{CFN}=120$ ppm) using RatioCH and RatioNH, respectively. These two values, 174 and $120 \mathrm{ppm}$, in turn serve as indirect references in ${ }^{13} \mathrm{CO}$ and ${ }^{15} \mathrm{~N}$ dimensions.

The ${ }^{15} \mathrm{~N}-{ }^{1} \mathrm{H}$ two dimensional spectra of a ${ }^{13} \mathrm{C}$ - and ${ }^{15} \mathrm{~N}$ double-labeled human ubiquitin in $90 \% \mathrm{H}_{2} \mathrm{O} / 10 \% \mathrm{D}_{2} \mathrm{O}$ with and without AOR are shown in Figure 4. The two spectra look identical, approving the scheme of AOR. The results obtained in ${ }^{13} \mathrm{C}$ - ${ }^{1} \mathrm{H}$ two dimensional spectrum (not shown) also confirmed the method of AOR.

The method of AOR can also be applied to direct measurement of nuclei other than ${ }^{1} \mathrm{H}$, where the first decouple channel may be used for proton. For Varian NMR instrument, the offset (dof) is set on-resonance to $\mathrm{H}_{2} \mathrm{O}$, where dof is the same as the tof that is derived from the single pulse experiment (Figure 3 ). The NMR

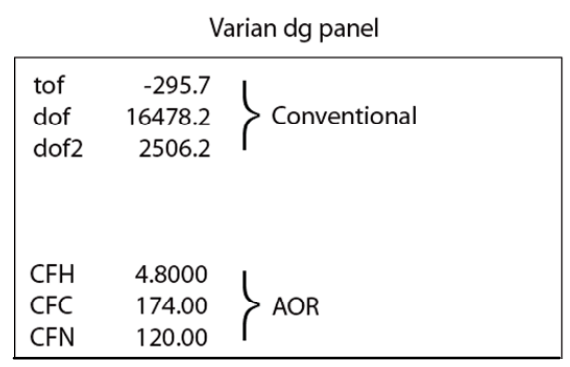

Figure 2. Part of a Varian dg panel, where $\mathrm{CFH}, \mathrm{CFC}$, and CFN in ppm are added for running experiments with AOR. 


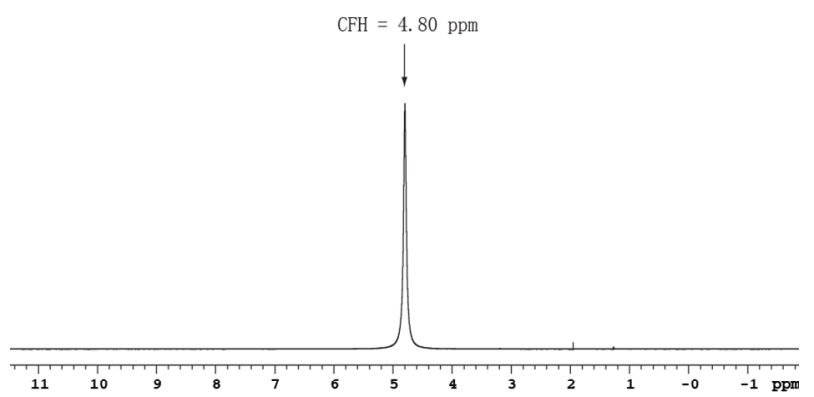

Figure 3. $\mathrm{H}_{2} \mathrm{O}$ spectrum of a ubiquitin sample in $90 \% \mathrm{H}_{2} \mathrm{O} / 10 \%$ $\mathrm{D}_{2} \mathrm{O}$ obtained by a Varian $750 \mathrm{MHz}$ NMR System with a $15^{\circ}$ pulse, 4 scans, $4 \mathrm{~s}$ acquisition time, $10 \mathrm{kHz}$ spectral width, and a zero-filling to $264 \mathrm{k}$. The RF carrier frequency is placed exactly on the water peak using a Varian commend movetof. After running the experiment, the transmitter offset tof = $-275.4 \mathrm{~Hz}$ is obtained.

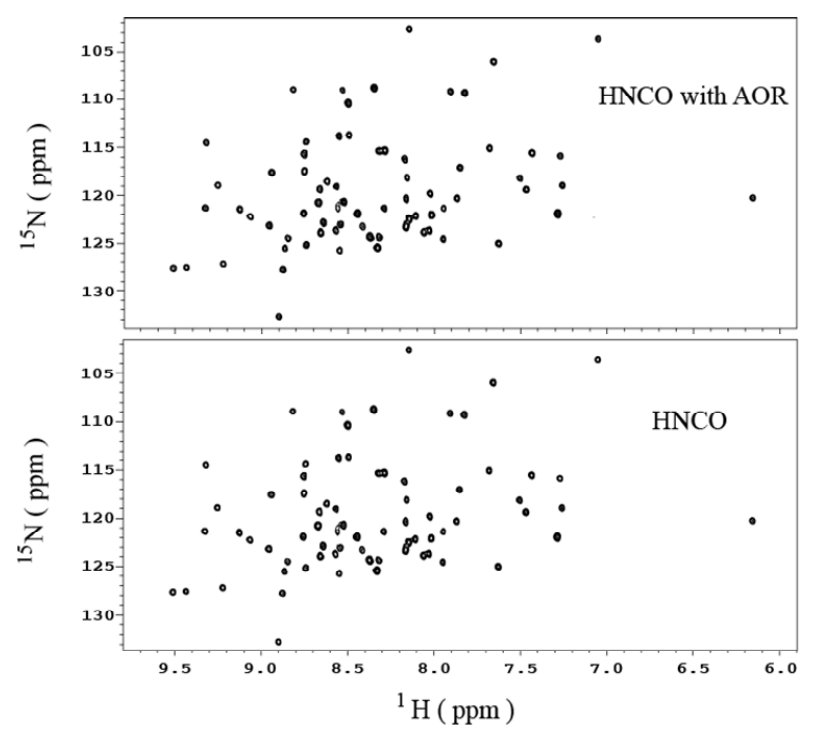

Figure 4. ${ }^{1} \mathrm{H}-{ }^{15} \mathrm{~N}$ two dimensional NMR spectra of a ${ }^{13} \mathrm{C}$ - and ${ }^{15} \mathrm{~N}$-double-labeled ubiquitin obtained from a gradient-enhanced HNCO experiment with (top) and without (bottom) AOR. Four scans per increment and 84 increments are used for both spectra. The sample has a concentration of $0.98 \mathrm{mM}$ and is in $90 \% \mathrm{H}_{2} \mathrm{O} / 10 \% \mathrm{D}_{2} \mathrm{O}$ with $50 \mathrm{mM}$ phosphate, $1 \mathrm{mM} \mathrm{NaN}_{3}$, and $\mathrm{pH} 5.0$.

spectra shown in Figure 5 are obtained through direct detection of ${ }^{15} \mathrm{~N}$ magnetization with AOR. The spectrum at the bottom was obtained with $\mathrm{CFH}=4.80 \mathrm{ppm}$ and $\mathrm{CFN}=120 \mathrm{ppm}$. Under this condition, the carrier frequency of ${ }^{15} \mathrm{~N}$ is calculated using the RatioNH and placed exactly at $120 \mathrm{ppm}$ just before pulsing. As a result, the center of the spectrum is $120 \mathrm{ppm}$, which serves also as an indirect reference. To demonstrate the effect of the error-inheritance, CFH was misplaced by $0.1 \mathrm{ppm}$ from 4.80 to $4.90 \mathrm{ppm}$, correspondingly the ${ }^{15} \mathrm{~N}$ peak shifts the same amount as predicted by the error-inheritance (Eq.4).

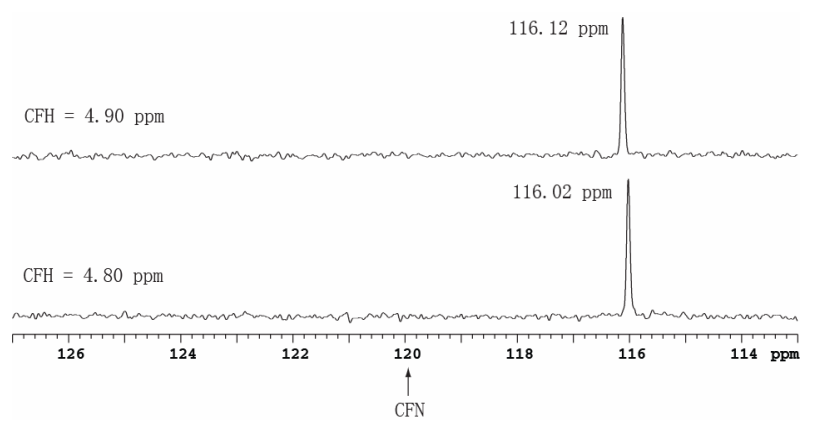

Figure $5 .{ }^{15} \mathrm{~N}$ directly detected spectra with AOR of a ${ }^{15} \mathrm{~N}$ - and ${ }^{13}$ C-labeled Acytel-glycine, where CFN = 120 ppm for both spectra.

\section{CONCLUTIONS}

In multidimensional NMR, the ratio between carrier frequencies can be expressed as

RatioXH $=R_{\mathrm{XH}}(0)\left[\left(\mathrm{CFX}+10^{6}\right) /\left(\mathrm{CFH}+10^{6}\right)\right]$. From the ratio, the required offset for a desired $\mathrm{CFX}$ can be generated by the NMR instrument as long as CFH is referenced. In this way, the centers of the indirectly detected dimensions can be inputted in ppm rather than in frequencies. Given the temperature dependence of the reference molecule, AOR can be easily extended to temperatures beyond $25^{\circ} \mathrm{C}$, at which the frequency ratio is defined.

For nuclei other than ${ }^{13} \mathrm{C}$, indirect referencing may cause conflict when two measured ratios $R_{\mathrm{XH}}^{\mathrm{DSS}}(0)$ and $R_{\mathrm{XH}}^{\mathrm{TMS}}(0)$ are used. To avoid this, only one of the two ratios needs to be measured and the other should be calculated based on the relationship between the two standards.

Since the error $(\triangle \mathrm{CFH})$ arising from improper referencing of ${ }^{1} \mathrm{H}$ is handed down to the $\mathrm{X}$ nucleus, i.e., $\Delta \mathrm{CFX} \approx \Delta \mathrm{CFH}$, the accuracy of the indirect referencing relies solely on the ${ }^{1} \mathrm{H}$ referencing, which is much easier to handle, especially for experiments with inverse detection.

AOR can be applied not only to experiments with inverse detection but also to direct detection of $\mathrm{X}$ nuclei with proper referencing. It is indispensable in research and industry, where slight differences of chemical shifts among different molecules need to be identified or large number of samples need to be run and analyzed daily.

\section{ACKNOWLEDGEMENTS}

This research was supported by the Sealy Center for Structural Biology, University of Texas Medical Branch at Galveston, East China Normal University, and National Fundamental Research Project of China (2007CB925200).

\section{REFERENCES}

[1] Abragam, A. (1961) Principles of nuclear magnetism. 
Clarendon Press, Oxford.

[2] Ernst, R.R., Bodenhausen, G. and Wokaun, A. (1987) Principles of nuclear magnetic Resonance in one and two dimensions. Clarendon Press, Oxford.

[3] Mehring, M. (1976) High resolution NMR spectroscopy in solids. Springer, Berlin.

[4] Harris, R.K., Becker, E.D., Menezes, S.M.C., Goodfellow, R. and Granger, P. (2002) NMR nomenclature: Nuclear Spin properties and conventions for chemical shifts. Solid State Nuclear Magnetic Resonance, 22, 458-583. doi:10.1006/snmr.2002.0063

[5] Harris, R.K., Becker, E.D., Menezes, S.M.C., Robin, G. and Pierre, G. (2001) NMR nomenclature. Nuclear spin properties and conventions for chemical shifts. Pure and Applied Chemistry, 73, 1795-1818. doi:10.1351/pac200173111795

[6] Harris, R.K., Becker, E.D., Menezes, S.M.C., Granger, P., Hoffman, R.E. and Zilm, K.W. (2008) Further conventions for NMR shielding and chemical shifts. Pure and Applied Chemistry, 80, 59-84. doi:10.1351/pac200880010059

[7] Wisharf, D.S., Bigam, C.G., Yao, J., Abildgaard, F., Dyson, H.J., Oldfield, E.E., Marklev, J.L., Brian, D. and Svkes, B.D. (1995) ${ }^{1} \mathrm{H},{ }^{13} \mathrm{C}$ and ${ }^{15} \mathrm{~N}$ chemical shift referencing in biomolecular NMR. Journal of Biomolecular NMR, 6, 135-140.

[8] Live, D.H., Davis, D.G., Agosta, W.C. and Cowburn, D. (1984) Long range hydrogen bond mediated effects in peptides: Nitrogen-15 NMR study of gramicidin S in water and organic solvents. Journal of the American Chemical Society, 106, 1939-1941. doi:10.1021/ja00319a006
[9] Edison, A.S., Abildgaard, E., Westler, W.M., Mooberry, E.S. and Markley, J.L. (1994) Practical introduction to theory and implementation of multinuclear, multidimensional nuclear magnetic resonance experiments. Methods in Enzymology, 239, 3-79. doi:10.1016/S0076-6879(94)39003-7

[10] DeMarco, A. (1996) pH dependence of internal references. Journal of Magnetic Resonance, 26, 527-528.

[11] Markley, J.L., Bax, A., Arata, Y., Htlbers, C.W., Kaptein, R., Sykes, B.D., Wright, P.E. and Wuthrich, K. (1998) Recommendations for the presentation of NMR structures of proteins and nucleic acids. Pure and Applied Chemistry, 70, 117-142. doi:10.1351/pac199870010117

[12] Markley, J.L., Bax, A., Arata, Y., Hilbers, C.W., Kaptein, R., Sykes, B.D., Wright, P.E. and Wuthrich, K. (1998) Recommendations for the presentation of NMR structures of proteins and nucleic acids. Journal of Molecular Biology, 280, 933-952. doi:10.1006/jmbi.1998.1852

[13] Hoult, D.I. (1978) The NMR receiver: A description and analysis of design. Progress in Nuclear Magnetic Resonance Spectroscopy, 12, 41-77. doi:10.1016/0079-6565(78)80002-8

[14] Maurer, T. and Kalbitzer, H.R. (1996) Indirect referencing of ${ }^{31} \mathrm{P}$ and ${ }^{19} \mathrm{~F}$ NMR spectra Journal of Magnetic Resonance, B113, 177-178. doi:10.1006/jmrb.1996.0172

[15] Keifer, P. A. (1999) 90 degrees pulse width calibrations: How to read a pulse width array? Concepts in Magnetic Resonance, 11, 165-180. doi:10.1002/(SICI)1099-0534(1999)11:3<165::AID-CM $\underline{\mathrm{R} 4>3.0 . \mathrm{CO} ; 2-\mathrm{D}}$ 